BULLETIN Bulletin hispanique

HispaniQuE Université Michel de Montaigne Bordeaux

$110-2$ | 2008

Varia

\title{
Refranes y romances: un camino en dos direcciones
}

Hugo O. Bizzarri

\section{(2) OpenEdition}

\section{Journals}

Edición electrónica

URL: http://journals.openedition.org/bulletinhispanique/743

DOI: 10.4000/bulletinhispanique.743

ISSN: 1775-3821

Editor

Presses universitaires de Bordeaux

\section{Edición impresa}

Fecha de publicación: 1 diciembre 2008

Paginación: 407-430

ISBN: 978-2-86781-543-0

ISSN: 0007-4640

\section{Referencia electrónica}

Hugo O. Bizzarri, «Refranes y romances: un camino en dos direcciones », Bulletin hispanique [En línea], 110-2 | 2008, Publicado el 01 diciembre 2011, consultado el 19 abril 2019. URL : http://

journals.openedition.org/bulletinhispanique/743; DOI : 10.4000/bulletinhispanique.743 


\title{
Refranes y romances: un camino en dos direcciones
}

\author{
Hugo O. Bizzarri \\ Université de Fribourg-Suisse
}

Ce travail étudie les multiples relations qu'ont maintenues proverbes et romances, à la faveur de l'utilisation dans les deux genres de formes phraséologiques communes. Ce contact est analysé à travers des versions déjà diffusées au XIV siècle et il est possible d'en conclure que ce croisement fut bien antérieur à la lexicalisation de vers de romances ainsi qu'à leur entrée dans les recueils de proverbes classiques. D'un autre côté, l'examen de diverses versions d'un même romance permet d'observer que l'insertion de proverbes n'a pas nécessairement besoin de se produire au moment même de la création de la ballade, mais quelle est une conséquence de sa performance.

Este trabajo estudia las múltiples relaciones que han tenido refranes y romances, facilitadas por la utilización en ambas especies de formas fraseológicas comunes. Se rastrea este contacto en versiones ya difundidas en el siglo XIV y se llega a la conclusión de que este cruce fue muy anterior a la lexicalización de versos de romances y a su entrada en los refraneros clásicos. Por otra parte, el estudio de diversas versiones de un mismo romance permite observar que la inserción de refranes no tiene por qué producirse en el momento mismo de creación de la balada, sino que es una consecuencia de su performance.

This study explores the many connections woven between proverbs and romances owing to the use, in both genres, of a common type of phrases. This contact is analyzed in versions that already circulated during the fourteenth century, which leads us to conclude that the junction between these two genres happened much earlier than the lexicalization of romance verses and their insertion into collections of classical proverbs. On the other side, studying various versions of the same romance allows us to observe that the introduction of proverbs does not necessarily need to take place at the moment when the ballad is created, but is a consequence of the ballad's performance.

Mots clés : Moyen Âge - Romancero - Proverbes - Lyrique.

$B H i$, Tome 110, n 2 - décembre 2008 - p. 407 à 430. 
T A RELACIÓn del refranero con la lírica ya ha sido reiteradamente Leñalada ${ }^{1}$. Sabido es que desde el primer cuarto del siglo XIV se empleaba en Castilla ya la voz refrán con el sentido de estribillo, heredera del provenzal refrain, como hace don Juan Manuel en su Libro de las tres razones ${ }^{2}$. Este primer contacto que se dio a nivel lingüístico derivó posteriormente en práctica habitual. Desde los poemas de Alfonso de Villasandino en el Cancionero de Baena hasta el Cancionero de Hernando del Castillo, el recurso de utilizar refranes se transformó en una moda: sea la simple intercalación discontinua de refranes, su inserción como estribillos o la composición de poemas sobre la base exclusiva de refranes, la utilización de paremias en la lírica se convirtió en un juego cortesano. Las raíces de esa práctica no eran nuevas y se han señalado diversos orígenes. Eleanor O’Kane hizo referencia a una práctica que se había manifestado ya en varios autores medievales: Juan Ruiz, Alfonso Martínez de Toledo y Fernando de Rojas; mientras que Brian Dutton la consideró como una clara influencia de la devotio moderna ${ }^{3}$. De una forma u otra, los caminos de la lírica y el refranero se cruzaron.

Al costado de estas consideraciones ha quedado una relación advertida ya por Ramón Menéndez Pidal: la proverbialización de versos de romances ${ }^{4}$. Advertía el filólogo que durante los siglos XVI a XVII los romances comenzaron a ser utilizados como elementos fraseológicos del lenguaje. Las primeras noticias las databa en el año 1520, recordando la costumbre de Hernán Cortés de intercalar en su conversación versos de romances y la reacción de sus soldados de responderle de la misma manera. Así, los romances afluían en la conversación cotidiana. Esta costumbre se conservó hasta la segunda mitad del siglo XVII: conforme los romances fueron cayendo en desuso, el uso fraseológico de los romances también decayó.

1. A. Taylor, The Proverb and an Index to the Proverb. Ed. Wolfang Mieder, Bern-FrankfurtNew York, 1985 ( $1^{\circ}$ ed. Cambridge, Hardvard UP, 1931), p. 32-34, E. S. O’Kane, Refranes y frases proverbiales de la Edad Media, Madrid, BRAE Anejo 2, 1959, p. 28-33, Margit Frenk, «Refranes cantados y cantares proverbializados», NRFH, $15 \mathrm{~N}^{\circ} 1-2$ (1961), p. 155-168 (reimp. en Estudios sobre lírica antigua, Madrid, Castalia, 1978, p. 154-171), L. Combet, Recherches sur le Refranero castillan, París, Société d'Édition Les Belles Lettres, 1971, p. 49-55, B. Dutton, «Proverbs in Fifteenth-Century Cancioneros», en A. Deyermond y I. Macpherson (eds.), The Age of the Catholic Monarchs, 1474-1516: Literary Studies in Memory of Keith Whinnom, Liverpool, Liverpool UP, 1989, p. 37-47, H. O. Bizzarri, El refranero castellano en la Edad Media, Madrid, Laberinto, 2004, p. 169-192.

2. E. S. O'Kane, "On the Names of the refrán», HR, $18 \mathrm{~N}^{\circ} 1$ (1950), p, 1-14, L. Combet, op. cit., p. 11-61, H. O. Bizzarri, op. cit., p. 19-40.

3. E. S. O'Kane, Refranes y frases proverbiales españolas..., p. 28; B. Dutton, op. cit., p. 46.

4. R. Menéndez Pidal, Romancero Hispánico (Hispano-Portugués, Americano y Sefardí). Teoria e Historia, Madrid, Espasa-Calpe, 1953, vol. 2, p. 184-189. 
Las reflexiones de Menéndez Pidal me llevaron hace tiempo a advertir estrechos puntos de contacto entre la evolución del refranero y el romancero ${ }^{5}$. Curiosamente, la primera atestación de ambas tradiciones plantea ciertas coincidencias: una versión del romance "La dama y el pastor» (Primavera $\mathrm{N}^{\circ}$ $145)^{6}$ documentada por el estudiante mallorquí Jaume de Olesa y una ristra de refranes conocida como Romancea proverbiorum, ambos en cuadernos de apuntes de estudiantes, ambos incidentales, ambos, en fin, fuera de Castilla ${ }^{7}$. Más allá de este paralelismo azaroso muchos de los fenómenos de utilización, transmisión y evolución de ambas especies son comunes y el conocimiento de una puede ayudar al conocimiento de la otra. Advertía en aquella oportunidad la necesidad de estudiar el refranero hispánico unido a otras manifestaciones populares ${ }^{8}$.

Estudios recientes han vuelto sobre esta relación en dos romances de la tradición moderna. El primero revisa una versión de «El infante cautivo» ("Carcelero por tu vida») que repite tres veces un refrain: «Mas vale fortuna en tierra que no bonanza en mar». Su editora seńala que «El refrán aparece en varias colecciones paremiológicas judeoespañolas (Galante 1902, Besso 1935, Galimir 1951, Sparto y Beja 1957, Molho 1960 y Moscona 1981) -aunque no sabemos en qué sentido se aplicaba entre sefardíes-, pero falta en la mayoría de los principales refraneros españoles y en el romancero peninsular. Sólo consta en el Vocabulario de refranes de Gonzalo Correas»?.

5. H. O. Bizzarri, «Oralidad y escritura en el refranero medieval», Proverbium 12 (1995), p. 27-66 (incorporado casi en su totalidad al capítulo 3 de mi El refranero castellano en la Edad Media, p. 41-65).

6. Los romanceros a los que haré referencia son: F. J. Wolf y C. Hofmann, Primavera y flor de romances o colección de los más viejos y más populares romances castellanos, Berlín, A. Asher y Comp., 1856, 2 vols., M. Menéndez y Pelayo, Antología de poetas líricos, T. 8 y 9, Madrid, Librería de Hernando y Compañía, 1899; Cancionero de romances (Anvers, 1550). Ed. A. Rodríguez-Mońino, Madrid, Castalia, 1967; Juan de Escobar, Historia y romancero del Cid (Lisboa, 1605). Ed. A. Rodríguez-Moñino, Madrid, Castalia, 1973; G. Di Stefano, Romancero, Madrid, Taurus, 1993 y P. Díaz-Mas, Romancero, Barcelona, Crítica, 1994.

7. Rius Serra, «Refranes del siglo XIV», RFE, 13 (1926), p. 364-372; E. Levi, «El romance florentino de Jaume de Olesa», RFE, 14 (1927), p. 134-160; C. V. Aubrun, «Le romance Gentil dona gentil dona. Une enigme littéraire», Iberoromania, 18 (1983), p. 1-8; F. Rico, «Los orígenes de Fontefrida y el primer romancero trovadoresco", en Texto y contextos. Estudios sobre la poesía española del siglo XV, Barcelona, Crítica, 1990, p. 1-32.

8. De hecho, gran parte de mi libro El refranero castellano en la Edad Media es el estudio de las relaciones del refrán con diversos ámbitos de la cultura medieval.

9. Aviva Garriba, «Romancero y refranero : el romance del Infante cautivo», en A. M. Beresford y A. Deyermond (eds.), Preceeding of the Ninth Colloquium, Londres, Department of te Hispanic Studies-Queen Mary and Westfiel College, 2000, p. 211-222, esta cita en p. 218. 
Efectivamente, Correas lo incorpora sin decir que es un verso de romance, justamente porque ya estaría totalmente asimilado a la fraseología española. Así más bien confirma el proceso advertido por Menéndez Pidal: el verso de este romance se proverbializó entre las comunidades sefardíes y, de ahí, su entrada a las colecciones modernas judeoespańolas y su ausencia, por tanto, en los refraneros clásicos. El otro romance estudiado es una versión argentina del romance de «La dama y el pastor» en el cual se hallan dos refranes («Darle a otro perro ese hueso» v. $6 \mathrm{y}$ «El buey solo bien se lame» v. 12) y una frase proverbial («No se me da un cuidado» v. 3), cruce que no se daba en versiones antiguas de este romance ${ }^{10}$. Ambos testimonios, aunque de tema tradicional, pertenecen a la tradición moderna. Creo, no obstante, que es posible detectar estos contactos ya en la tradición antigua. $\mathrm{Y}$, de hecho, dos versiones glosadas del siglo XVI de este último romance derivadas de un villancico con glosa de Alcaudete, una la de un pliego suelto gótico de Madrid titulada "Coplas de vna dama y vn pastor» (Ms. BN Madrid R 9439) y otra la de un pliego suelto gótico impreso en Granada por Hugo de Mena en 1573 titulada «Romance de una hermosa Xarifa y Abindarráez» (Cracovia, Biblioteca Jagiellonska: CIM E 13), incorporan estos mismos refranes ${ }^{11}$.

\section{Dos géneros, una misma fraseología}

¿Cómo explicar este cruce entre refranes y romances? Partamos de un elemento seguro: ambos comparten similares fórmulas expresivas. Mucho se ha discutido sobre la posible existencia de un "estilo proverbial» ${ }^{12}$. La

10. Gloria Chicote, «Temas medievales en el romancero tradicional argentino : paremias y mensaje dirigido en una versión de La dama y el pastorn, en S. Grundwald, C. Hammerschmidt y G. Nilson (eds.), Pasajes, Passages, Passagen. Homenaje a Christian Wentzlaff-Eggebert, Sevilla, 2004, p. 405-411.

11. Habría que preguntarse si la versión argentina tiene algún entronque con éstas. Véanse ambas versiones en Diego Catalán, La dama y el pastor. Romance, villancico, glosa, Madrid, Gredos, 1978, vol. 1, p. 66-73 y 75-88.

12. Véase sobre esto A. Dundes, «On the Structure of the Proverb», Proverbium, 25 (1975), p. 961-973 (reimp. en W. Mieder y A. Dundes, The Wisdom of Many. Essays on the Proverb, New York, Garland Publishing, 1981, p. 43-64), B. Holbek, "Proverb Style», Proverbium, 15 (1970), p. 470-472, S. Arora, «The Perception of Proverbiality», Proverbium, 1 (1984), p. 1-38 (reimp. en W. Mieder, Wise Words. Essays on the Proverb, New York-London, Garland Publishing, 1994, p. 3-29) y H. O. Bizzarri, "Anatomía de la expresión proverbial», en Estudios sobre la variación textual. Prosa castellana de los siglos XIII a XVI, Buenos Aires, Secrit, 2001, p. 25-50. 
descripción de este estilo proverbial ha importado más que para describir el refrán en sí, para determinar si una formulación que se documenta por primera (y tal vez única) vez es proverbial o no. Los refranes evidentemente se sirven de estructuras fijas de expresión, lo que en otras partes llamé «esquemas generativos» ${ }^{13}$, que brindan la posibilidad de acuñar la expresión proverbial: la estructura bimembre, la igualdad de miembros $(A=B)$, o su desigualdad $(A \neq B)$, estructuras ponderativas como «más vale [esto] que [aquello]», "más quiero [esto] que aquello», «mejor es [esto] que [aquello]», los comienzos «el que...», "el que non...», "quien...» siempre en estructura bimembre, etc., o rasgos de estilo como la sustantivación de infinitivos, la formulación elíptica, la elisión de artículo, la combinación de tiempos verbales, la utilización de arcaísmos, la ubicación del verbo en la frase, etc., son elementos todos que ayudan a la creación del estilo proverbial y, con ello, a la identificación de la paremia dentro del discurso. Pero esto trae consigo una consecuencia: se puede aprender el estilo proverbial para la creación de falsos refranes, los llamados pseudorefranes de los que tanto los Proverbios morales de Sem Tob como el Libro de buen amor de Juan Ruiz están llenos.

También el romancero tiene un estilo propio, el que Menéndez Pidal definió como «estilo tradicional» y cuya principal característica es ser intuitivo ${ }^{14}$. Esta peculiaridad lleva a los romancistas a utilizar frecuentes fórmulas para reactualizar su relato. Algunas son privativas del romancero, pero otras se sirven de las mismas estructuras que se manejan en el refranero. Los romancistas se sirven de estas estructuras para expresar de manera sentenciosa una moral caballeresca, como ocurre en el romance «Riberas de Duero arriba» (Antología $\mathrm{N}^{\circ}$ 42), que narra el reto de los caballeros zamoranos Diego Ordóñez y su hijo don Fernando, quien antes del momento de la lucha anima a su hijo diciéndole: «mas vale morir con honra que non vivir deshonrado» (p. 77). La misma estructura recrea el romance de Rodrigo de Lara, «Ay Dios que buen caballero» (Antología N²0), cuando dońa Lambra exclama: "Adamad, dueñas, amad cada cual de buena gana / que mas vale un caballero que cuatro de los de Salas / que cuarenta ni cincuenta de los de Córdoba la llana» (p. 40). En el «Romance de la embajada que envio Danes Urgeo» el Conde Dirlos tiene la difícil embajada de decirle al emperador Carlos que su hijo ha matado a Baldovinos. El emperador sentencia: «mas quiero dexar memoria / de grande riguridade / que dexar sin dar castigo /

13. Véase H. O. Bizzarri (ed.), Íñigo López de Mendoza, Marqués de Santillana. Refranes que dizen las viejas tras el fuego, Kassel, Edition Reichenberger, 1995, p. 16-46; idem, El refranero castellano en la Edad Media..., p. 57-63.

14. R. Menéndez Pidal, Romancero hispánico, vol. 1, p. 58-60; J. Szertics, Tiempo y verbo en el romancero viejo, Madrid, Gredos, 1967. 
al que comete maldade» (Cancionero de romances, p. 142); el juramento que hace el Conde Claros al rey si no le da ayuda: «mas quiero perder la vida / que yo tal vida pasar»; "Romance de don Claros de Montalbán» (Antología $\mathrm{N}^{\circ}$ 192, p. 144), la respuesta del Conde Claros justificando sus amores con Claraniña: «quien non ama las mujeres non se puede hombre llamar» en el romance «Media noche era por filo» (Antología N 190, p. 137) o "quien por traidores ruega / traidor se puede llamar» del «Romance del conde Grimaltos y su hijo Montesinos» (Antología $\mathrm{N}^{\circ} 175$, p. 78). Todas estas son formas expresivas comunes al refranero. Hay otros versos que, sin repetir estas estructuras básicas, parecen a todas luces formulaciones proverbiales, como el verso «Los yerros por amores / dignos son de perdonar» del «Romance del Conde Claros de Montalbán» (Cancionero de romances, p. 170), "cauallero que va en armas / de muger no deue curare» del "Conde Dirlos» (Cancionero de romances, p. 115), "el bien de la libertad / por ningun precio es comprado» del «Romance de los cinco maravedíes» (Antología N 61, p. 115), «ninguno por riqueza / no se debe de ensalzar» del «Romance del conde Grimaltos y de su hijo Montesinos» (Antología N 175, p. 73). Del «Romance del Conde Claros de Montalbán», "Media noche era por filo» (Cancionero de romances, p. 174), ya hemos notado que algunos de sus versos entraron a la fraseología popular («Media noche era por filo» y «Los yerros por amores / dignos son de perdonar»). El romance, además, está lleno de versos proverbiales: «quien non ama las mugeres / no se puede hombre llamar» (p. 171), «los reyes con furor / no deuen de sentenciar» (p. 172), "firmeza de mugeres / no puede mucho durar» (p. 173), «la vida está en la muerte / y en la muerte el descansar» (p. 174), etc. Este romance es un ejemplo palpable de la utilización de una fraseología común entre ambos géneros, tanto que se torna fácil la creación de pseudorefranes.

Inútil es buscar cualquiera de estos versos en una colección de proverbios antigua o moderna. No se trata de refranes sino siempre de versos que transmiten una moral cortesano-caballeresca utilizando modos expresivos comunes a uno y otro género.

En definitiva, refranes y romances comparten formas expresivas. No era ilógico, pues, que sus caminos se cruzaran, que refranes se introdujeran en romances y que romances desembocaran en expresiones lexicalizadas.

\section{Los romances como elementos fraseológicos}

La colección de Refranes que dizen las viejas tras el fuego del Marqués de Santillana en sus 724 refranes incluye algunos estribillos líricos; sin embargo, ninguno pertenece a un romance, forma poética que no fue tenida en cuenta 
tampoco por sus continuadores anónimos ${ }^{15}$. Tampoco se halla nada parecido ni en Pedro Vallés ni en Mal Lara. El único que da cabida a este tipo de versos es Gonzalo Correas en su Vocabulario de refranes y frases proverbiales compilado hacia 1627. En por lo menos nueve ocasiones indica que el refrán que glosa proviene de un romance: "Hable en algaravia, como aquel que bien la sabe. Con esto, que es de un romance viejo, motejo a uno de morisco Garci Sanchez de Badajoz» (H 81) ${ }^{16}$. Se trata de uno de los más famosos versos del romance novelesco "Yo me era mora Morayma» que transmite el Cancionero de romances (p. 290). Otros ejemplos: "Hele, hele por do viene / el moro por la calzada. Del romance; y prosigue: borceguies marroquies / y espuelas de oro calzaba» (H 346) proviene del "Romance del rey moro que perdió a Valencia» (Cancionero de romances, p. 243); «Lanzada de moro izquierdo te atraviese el corazon. De un romance» (L 1028), verso del "Romance del Conde Lombardo»: "iAy, que linda que eres Alba!» (Antología $\mathrm{N}^{\circ} 136^{\mathrm{a}}$ ); «Mas envidia he de vos, conde, que mancilla ni pesar. Quedo de un cantar viejo: Si es ansi como se canta / que dormistes con la infanta, / mas envidia...» (M 357) del "Romance del conde Claros de Montalbán» (Cancionero de romances, p. 173-174); «Mas galan que Gerineldos. Tomose de aquel romance del Cid: Mas galan que Gerineldos, / salio el Cid famoso al patio, / dandole con sus caballeros / el rey le estaba aguardando... Los romances viejos celebran a Gerineldos por Galán enamorado» (M 363) que transmite el Romancero de Juan de Escobar (p. 134); "Pesame de vos, el conde. Quedo en refran de cantar viejo» (P 449), otra vez el «Romance del Conde Claros de Montalbán» (Cancionero de romances, p. 173); «Si lo dije no me acuerdo, no desdigo mi palabra. Del romance: Ruedan, si se te acuerda / que me diste la palabra, / que me darías a Jaen / en una noche ganada. / -Si lo dije no me acuerdo, / no desdigo mi palabra» (S 459) (Antología $\mathrm{N}^{\circ} 72$ ); "Madre la mi madre, guardas me poneis; que si yo no me guardo, mal me guardareis. Refran que salio de cantar» (M 22). Hay otras veces en que Correas no indica nada: "Los yerros por amores dinos son de perdonar» (L 1609) procedente del Conde Claros; "Mala la hubistes, franceses, la caza de Roncesvalles» (M 154) procedente del «Romance del Conde Guarinos» (Cancionero de romances, p. 180); «Ojos que le vieron ir, / no le veran mas en Francia; / ojos que le vieron ir, / no le veran mas venir»

15. H. O. Bizzarri, Refranes que dizen las viejas..., p. 15; idem, «La impresión de Valladolid, 1541 de los Refranes que dizen las viejas tras el fuego", en Homenaje a Germán Orduna, Alcalá de Henares, Servicio de Publicaciones, p. 111-122 e idem, «El manuscrito Zabálburu de los Refranes que dizen las viejas tras el fuego", Incipit, 24 (2004), p. 75-99.

16. Cito por Gonzalo Correas, Vocabulario de refranes y frases proverbiales (1627). Ed. L. Combet, Madrid, Castalia, 2000. 
(O 137) del romance « $\mathrm{O}$ h, Belerma!» (Cancionero de romances, p. 303), etc. La procedencia es variada: de romances novelescos, históricos, carolingios o fronterizos, no importa el tipo, todo verso de romance podía derivar en una frase lexicalizada.

Hay un caso, sin embargo, en que Correas indica el caso contrario, es decir, un refrán que desembocó en copla: «En gustos no hay disputa. Hízose copla, principio de romance: En los gustos no hay disputa, / ni en amor leyes que obliguen, / ni en las mugeres razon / que sus gustos las limite» (E 1671) ${ }^{17}$.

Hace ya tiempo que se ha señalado que los romances han jugado un papel fundamental en la creación del Quijote ${ }^{18}$. Cervantes no escatima poner versos de romances en boca de sus personajes a lo largo de toda la obra. Don Quijote responde al ventero con los versos «Mis arreos son las armas / mi descanso el pelear» ${ }^{19}$ para dar a entender los esfuerzos a los que un caballero andante está acostumbrado; cuando don Quijote y Sancho entran al Toboso de noche el narrador inicia el capítulo con el verso del «Romance del Conde Claros de Montalbán»: «Media noche era por filo» (p. 727); el narrador se vale de versos de un romance del cerco de Granada, «iTate, tate, folloncicos!» (p. 1290), para indicar que la historia de don Quijote sólo a él le toca narrarla. No dejan, naturalmente, de ser recursos literarios, pero tienen correspondencia con un proceso que se daba en los siglos XVI y XVII: la lexicalización de versos de romances, versos conocidos por todos y que de tanto repetirlos se habían desgajado de su conjunto textual y cargado de un nuevo valor semántico.

Un paso más. En pleno proceso de dignificación de la lengua vulgar, Sebastián de Covarrubias no dudaba en utilizar como documentación para su Tesoro de la lengua tanto refranes como romances, a los que se refiere como "cantarcillo viejo» o simplemente "cantarcillo» ${ }^{20}$.

17. Incorporado por M. Frenk a su Corpus de antigua lirica popular hispánica (siglos XVXVII), Madrid, Castalia, 1990-1992, $\mathrm{N}^{\circ} 1750$.

18. R. Menéndez Pidal, «Un aspecto de la elaboración del Quijote», en De Cervantes y Lope de Vega, Espasa-Calpe, Buenos Aires-México, 1948, p. 9-56; M. Chevalier, "Cervantes frente a los romances viejos», Voz y Letra, 1 (1999), p. 191-196. Véase el comentario de cada uno de estos versos en la Gran Enciclopedia Cervantina, dir. Carlos Alvar, Madrid, Castalia, 2005.

19. Cito por Miguel de Cervantes Saavedra, Obra completa. Ed. de F. Sevilla Arroyo y A. Rey Hazas, Alcalá de Henares, 1995, T. 1, p. 53.

20. Sebastián de Covarrubias Orozco, Tesoro de la lengua castellana o española. Ed. C. R. Maldonado, Madrid, Castalia, 1994, p. 116 y 301 (s.v. argolla y cerca). Sobre este autor véase Karl-Ludwig Selig, «The Proverbs in Sebastián de Covarrubias Tesoro de la lengua castellana» Proverbium 9 (1967), p. 213. 


\section{Los refranes como versos de romances}

Podemos retroceder aún más buscando los contactos entre romances y refranes. Tomemos como punto de referencia la segunda edición que Martín Nucio hizo de su Cancionero de romances, en Amberes, ańo de 1555. Por lo que nos muestra la documentación, la inserción de versos proverbiales en el cuerpo de romances es anterior a la lexicalización de versos de romances. El Cancionero de Martín Nucio publicado en Amberes presenta ya este cruce.

Recorriendo dicho cancionero, la primera composición que presenta este fenómeno es el «Romance del Conde Dirlos». Este extenso poema de carácter juglaresco y tradicional fue calificado por Menéndez Pidal como «un verdadero cantar de gesta» de origen primitivo, anterior al siglo XV, tal vez inspirado en algún viejo y perdido romance tradicional de boda estorbada o en una balada extranjera sobre dicho tema ${ }^{21}$. El romance contiene seis versos proverbiales, de los cuales tres son pseudorefranes, dos verdaderos refranes y una frase proverbial. El poema se inicia con el drama de la despedida dolorosa de los jóvenes esposos. El Conde Dirlos aconseja a su esposa esperar siete años y, si él no regresare en ese tiempo, le permite casarse. Es un caballero y está obligado a ir a la guerra, pues «cauallero que va en armas / de muger no deue curare» (p. 115). Estos versos presentan una construcción sintáctica que les da estatuto proverbial: no se trata en sí de un refrán tradicional, sino de unos versos compuestos a manera de sentencia con los que se condensa un ideal caballeresco. Sigue el romance: viaje de los esposos a París e ida del Conde a luchar contra los moros entre los que obtiene grandes victorias. Luego de quince años en tierra de moros el conde siente añoranza por su esposa y por su tierra. Reúne a sus tropas y comienza una arenga:

$$
\begin{aligned}
& \text { [...] yo conozco aquel exemplo } \\
& \text { que dizen y que es verdade } \\
& \text { que todo hombre nacido } \\
& \text { que es de hueso y de carne } \\
& \text { el mayor deseo que tenia } \\
& \text { era en sus tierras holgare (p. 118) }
\end{aligned}
$$

Detrás del estilo romanceril (uso de la «-e» paragogica y del imperfecto) la formulación revela lo que anuncia el protagonista: se trata de un refrán popular. Samuel Singer identificó este refrán con el que presenta Petrus

21. R. Menéndez Pidal, Romancero hispánico, vol. 1, p. 275-285. Los paralelos con la balada europea han sido estudiados por W. J. Entwistle, «El Conde Dirlos», Medium Avum, 10 (1941), p. 1-14. 
Blesensis en su Epistola 160: "Cui non licet in patria vivere, saltem liceat sepelire ${ }^{22}$. Esto indicaría que estamos en presencia de un refrán difundido ya en Francia, como el motivo del romance. Podemos ir más lejos y conjeturar que el refrán latino tal vez se haya originado a partir del Salmo 36: 3: «Inhabita terram et pasceris in diuitis eius ${ }^{23}$. Sigamos con el romance. Todos deciden volver; sólo el Conde prefiere hacerlo en secreto. Como ya han notado los estudiosos de este romance, aparece aquí el motivo de la vuelta del esposo. Encuentra sus tierras tomadas por el Infante Celinos y su esposa casada con él. Enfurecido, el Conde quiere saber quién asistió a las bodas y quién se excusó. Él quisiera matar a Celinos, pero sus hombres le aconsejan ir a las cortes que fueron convocadas: «conocereys quien bien os quiere / y quien vos queria male» (p. 121), versos que son una adaptación del mismo refrán que presenta Santillana en su colección: «Echate a enfermar: veras quien te quiere bien o quien te quiere mal», Refranes ${ }^{24}$. Este refrán no tiene paralelos en el resto de la Romania, pero proviene de la idea de que al amigo se lo conoce en la necesidad y en las obras: «Tempore felici non cognoscuntur amici; sorte patet misera quae sit dilectio vera», Eberhard, Graecismus (Ms. BNP lat. 15133, fol. 20r, c. 1270), «Nimis honorati sunt amici... Dicitur vulgariter: Mort n’a nul ami» (Ms. BNP lat. 14961, fol. 179r r) 25, «Selonc qe le prouerbe nous enseigne Loials amours se prouont a l'essai», Gower, Balades $(40,15)$, «Au besoing voiton qui bien aime», Fabliau du senateur de Rome (v. 340) ${ }^{26}$. El proverbio en

22. S. Singer et alii, Thesaurus proverbiorum medii aevi. Lexikon des Sprichwörter des romanisch-germanischen Mittelalters, Berlin-New York, Walter de Gruyter, 1995-1996, vol. VII, asiento 2.1.2.4. Man will in der Heimaterde begraben sein. Otros repertorios a los cuales haré referencia son: J. Morawski, Proverbes français antérieurs au XV siècle, París, Champion, 1925; H. Walther, Proverbia sententiaque latinitatis medii aevi. Lateinische Sprichwörter und Sentenzen des Mittelalters in alphabetischer Anordnung, Göttingen, Vandenhoeck \& Ruprecht, 1963-1967, 5 vols.; idem, Proverbia sententiaque latinitatis medii ac recentioris aevi. Lateinische Sprichwörter und Sentenzen des Mittelalters und der frühen Neuzeit in alphabetischer Anordnung. Neue Reihe, Göttingen Vandenhoeck \& Ruprecht, 1982-1986, 3 vols.; J. Werner, Lateinische Sprichwörter und Sinnsprüche des Mittelalters, aus Handschriften gesammelt, Heidelberg, Carl Winter Universitätverlag, 1966.

23. Sus recurrencias en S. Singer, op. cit., vol. 7, asiento 2.1.2.1. Man bleibe im eigenem Land.

24. H. O. Bizzarri (ed.), Refranes que dizen las viejas..., $\mathrm{N}^{\circ} 246$.

25. Citados por B. Hauréau, Notices et extraits de quelques manuscrits latins de la Bibliothèque Nationale, T. IV, París, Klincksieck, 1891, p. 172 y 283. Variante : «Tempore felice multi numeratur amici, / cum fortuna paret, nullus amicus erit» $\mathrm{H}$. Walther, op. cit., $\mathrm{N}^{\circ} 31228$ 31232, 43695 y 43695 .

26. Editado por D.-M. Méon, Nouveau recueil de fabliaux et contes inédits des poètes français des $X I I^{e}, X I I I^{e}, X I V^{e}$ et $X V^{e}$ siècles, T. II, París, Cuez Chasseriou, 1823 (reimp. Ginebra, Slatkine Reprints, 1976), p. 394-410. 
España se conoce desde Pedro Alfonso y tuvo mucha difusión especialmente entre las obras provenientes del árabe en el siglo XIII ${ }^{27}$.

El Conde se da a conocer ante el emperador cuando está a punto de lidiar con Celinos. Entonces introduce otro verso proverbial: «los malos caballeros / siempre presumen el male» (p. 125), se trata de un pseudorefrán que vuelve a encerrar un esquema de valores caballerescos. La situación en palacio se pone tensa. Los doce pares se dividen unos contra otros, Francia misma se divide. El emperador busca consejo para resolver la situación, pues «los buenos consejeros / aprouechan a la necesidade» (p. 128). El romance presenta, además, una frase proverbial: "porque los que mal se quieren / quando le quieren hazer pesare / luego le dan por los ojos» (p. 126) versión que sólo documentan los diccionarios: «Dar de ojos, es caer sobre el rostro» Covarrubias (s.v. ojo) y «Dar de ojos. Caer de pechos en el suelo», Autoridades (s.v. ojo $)^{28}$.

En definitiva, este romance de la materia de Francia nos presenta dos refranes tradicionales de extendida tradición en la Romania, una frase proverbial y tres ejemplos de pseudorefrán, versos sentenciosos que imitan el estilo de los refranes con los que se condensa la ética caballeresca del romancero. Los versos proverbiales en este romance no son, pues, materia accesoria, más bien encierran buena parte de su ideología.

El caso del «Conde Dirlos» no es único. El mismo fenómeno puede encontrarse en otros romances de materia carolingia contenidos en el Cancionero de romances. El «Romance del Marqués de Mantua» que comienza «De Mantua salió el Marqués» presenta también una situación tópica de la balada europea ${ }^{29}$ : el personaje se pierde en un bosque y tiene un encuentro fortuito (en este caso no es maravilloso), pues halla herido de muerte a su sobrino Baldovinos. Los elementos populares se suman en el lamento del héroe, por ejemplo, unos versos de una copla popular («ven muerte quando quisieris [sic] / no te quieras detardare / mas al que menos te teme / le huys por mas penare» (p. 136) y un refrán con el que expresa su profunda angustia: «siempre lo oy dezir / y agora veo ser verdade / que

27. Recurrencias en H. O. Bizzarri, Diccionario paremiológico e ideológico de la Edad Media (Castilla, siglo XIII), Buenos Aires, Secrit, 2000, asiento A.I.170.9 Prueba del amigo; S. Singer, op. cit., vol. 7, asientos 4.3.2. Wahre Liebe bewährt sich in der Not y 4.3.3. Wahre Liebe lässt sich an deu Werken erkennen.

28. Esta frase proverbial convivía ya con «quebrar el ojo» que se da en refranes como "quebrantar intrambos ojos por sonar una pestaña", Antón de Montoro, Cancionero. Ed. M. Ciceri, introducción de J. Rodríguez-Puértolas, Salamanca, Universidad de Salamanca, 1990, p. 167.

29. R. Menéndez Pidal, Romancero hispánico, vol. 1, p. 263. 
quien larga vida biue / mucho mal ha de pasare» (p. 136). La formulación más antigua de este refrán la podemos datar en el primer cuarto del siglo XIV: "Quien mucho ha de andar, mucho ha de prouar», Libro del caballero Zifar ${ }^{30}$. Otra versión la presenta Antón de Montoro en un poema burlesco contra F. Moxica o Toledo, ambos reyes de armas del rey Juan II:

$$
\begin{aligned}
& \text { Vos, en quien todo bien cabe, } \\
& \text { do la discreción trasunta, } \\
& \text { non vos pese mi pregunta, } \\
& \text { que quien más anda más sabe; } \\
& \text { declararme por compás } \\
& \text { una dubda que no sé: } \\
& \text { ¿quál querríades vos más; } \\
& \text { que se perdiesse la fe } \\
& \text { o la planta de Noé» (p. 309). }
\end{aligned}
$$

El origen de este refrán nos es desconocido, pero, puesto que expresa la idea del poder transformador del conocimiento, es posible que se relacione con el proverbio bíblico "Qui addit scientiam, addit et laborem», Eclesiastés 1: 18, aunque esta vez el saber no sea sinónimo de dolor. Este refrán no fue desconocido por Cervantes: «[...] el que larga vida vive mucho mal ha de pasar» (Quijote, II-XxxII, p. 808) ${ }^{31}$.

$\mathrm{Su}$ continuación, "De Mantua salen apriesa" (Cancionero de romances, p. 140-146), presenta la embajada del Conde Dirlos a la corte del emperador. Su misión no es fácil: debe decirle que su hijo Carloto mató a Baldovinos, pero el emperador no lo sabe y se muestra dispuesto a escucharlo, pues: «[...] al amigo y enemigo / siempre se deue escuchare / por amistad al amigo / y al otro por se auisare» (p. 141). Oída la demanda, el emperador reflexiona y promete hacer justicia. Hubiera preferido que fuera su hijo el que hubiera muerto, y concluye: «el morir es una cosa / que a todos es naturale / la memoria queda biua / del que muere sin fealdade / del que biue deshonrrado / se deue tener pesare / porque assi biuiendo muere / oluidado de bondade» (p. 142). Estos versos unen dos sentencias. La primera («el morir es una cosa / que a todos es naturale») proviene de una doble tradición, bíblica ("Omnis morimur», II Reyes 14: 14) y clásica («Debemur morti nos nostraque», Horacio, Ars poetica (v. 63) ${ }^{32}$ y «Deficit

30. Libro del cauallero Zifar (El Libro del Cauallero de Dios). Ed. Ch. Ph. Wagner, An Arbor, University of Michigan, 1929, p. 131.

31. Para este, como para otros casos, remito al comentario que hago de refranes en la Gran Enciclopedia Cervantina; otras variantes en H. Walther, op. cit., $\mathrm{N}^{\circ} 23821$ y 398404.

32. H. Walther, op. cit., $\mathrm{N}^{\circ} 5174$. 
omne quod nascitur», Quintiliano, Institutio Oratoria (5, 10, 79). Así la Edad Media heredó la idea de que todo lo que nace debe morir y de que la muerte nos es común a todos: "Lex universa est, quae iubet nasci et mori», Publilius, Sententiae ( $\left.{ }^{\circ} 15\right)^{33}$, «Omne namque quod nascitur moritur», Petrus Blesensis, Epistola 178 (II, 131), «Le filz Adam fault tous morir», J. Mielot $\left(\mathrm{N}^{\circ} 160\right)$ y «[...] es natural porque natural es el morir», Corbacho ${ }^{34}$. Esta idea era frecuentemente transmitida por las colecciones de sentencias castellanas $^{35}$, pero se trata fundamentalmente de un motivo extensamente desarrollado en la sermonística. Por ejemplo, véase el sermón $\mathrm{N}^{\circ} 12$ del manuscrito 40 de la Real Colegiata de San Isidoro: «[... ] dize a cada uno de nosotros, que somos mortales e abemos de morir e tenemos de pasar aquel dolor tan fuerte» ${ }^{36}$ o en el sermón $\mathrm{N}^{\circ} 50$ del manuscrito de la Biblioteca Universitaria de Salamanca 1854: «Pues la muerte non la podemos foir, que todo el mundo anda ${ }^{37}$. La otra retoma la difundida idea de la fama como una segunda vida del hombre ${ }^{38}$.

El último romance de esta serie es el «Romance de la sentencia dada a don Carloto», "En el nombre de Iesus» (Cancionero de romances, p. 146-148), en el cual se dictamina: "quien mata ha de ser matado» (p. 147). Se trata de un refrán de carácter legal que no es sino una reelaboración de: «Quien mata, muera», Triste deleytaçion (p. 180) y éste a su vez de: «Qui tal faze tal prenda», Berceo, Milagros ${ }^{39}$, pero todos enraizados en la tradición del derecho consuetudinario $^{40}$.

33. H. Walther, op. cit., $\mathrm{N}^{\circ} 13716$.

34. Alfonso Martínez de Toledo, Arcipreste de Talavera o Corbacho. Ed. J. González Muela, Madrid, Castalia, 1970, p. 246. Más recurrencias en S. Singer, op. cit., vol. 9, asiento 1.3. Der Tod ist untrennbar mit dem Leben verbunden.

35. H. O. Bizzarri, Diccionario paremiológico..., asiento M.II.330.3 Nadie escapa a la muerte.

36. Pedro M. Cátedra, Los sermones en romance de la Real Colegiata de San Isidoro de León, Salamanca, Seminario de Estudios Medievales y Renacentistas, 2002, p. 179.

37. M. A. Sánchez Sánchez, Un sermonario castellano medieval. El Ms. 1854 de la Biblioteca Universitaria de Salamanca, T. 2, Salamanca, Universidad de Salamanca, 1999, p. 670.

38. Motivo estudiado en la literatura paremiológica por H. O. Bizzarri, «Non omnis moriar. Sobre la fama del sabio en la Edad Media castellana», Thesaurus (Boletín del Instituto Caro y Cuervo), Bogotá, 45 № 1 (1990), p. 174-179. Para una visión más general de esta temática en las letras hispánicas, véase de M. R. Lida de Malkiel, La idea de la fama en la Edad Media castellana, México, FCE, 1952.

39. Gonzalo de Berceo, Milagros de Nuestra Señora. Ed. de F. Baños, Barcelona, Crítica, 1997 , c. 250 d.

40. Véase para esto H. O. Bizzarri, "Formas primitivas del Derecho», en El refranero castellano en la Edad Media..., p. 125-133. 
El «Romance de don Gaiferos», «Assentado está Gayferos» (Cancionero de romances, p. 148-156), pese a su extensión, presenta un solo refrán. Se trata de un romance cuyo contacto con el Waltharius de San Gallen ha sido puesto de relieve: sin embargo, su relación con la balada europea es incuestionable ${ }^{41}$. El romance comienza presentando a Gaiferos olvidado de sus deberes de caballero, pues pasa sus días jugando al ajedrez mientras que su esposa permanece cautiva de los moros. El emperador le reprocha su olvido y, por tanto, decide ir a su rescate, pero no tiene armas. Se las pide a Roldán quien le niega su espada con el fin de probarlo:

$$
\begin{aligned}
& \text { Bien parece don Gayferos } \\
& \text { que soys de muy poca edad, } \\
& \text { bien oystes vn exemplo } \\
& \text { que conoceys ser verdad } \\
& \text { que aquel que bien os quiere } \\
& \text { aquel vos quiere castigar (p. 150). }
\end{aligned}
$$

Como bien indica el romance, se trata de un refrán tradicional que, sin embargo, no se documenta en Castilla antes del siglo XV. Era mucho más común por entonces en Francia y Alemania: "Qui bien ayme bien chastie» Morawski $\mathrm{N}^{\circ} 1836$ (Ms. BNP lat. 10360, s. XV), "Car qui bien ayme bien chatis, comme souvent nous l'oyez dire», Moralité nouvelle des enfants de Maintenant (segunda mitad del siglo XV), "Qui patitur sibi consuli, ille auxilium sperat; et contrario», Bebel, Proverbia germanica $\left(\mathrm{N}^{\circ} 348\right)$ y «Die man raden mach man helfen", Proverbia communia $\left(\mathrm{N}^{\circ} 257\right)^{42}$. Como ya indiqué en mi estudio general sobre refranes, la recurrencia de un mismo refrán en obras que aparentemente no han tenido contacto entre sí evidencia la existencia de un tronco común y es un signo de la antigüedad de la paremia. De todas formas, esto no nos revela si el contacto entre un refrán y una balada tradicional determinada es genético o pertenece a un momento de su reactualización.

$\mathrm{El}$ «Romance del Conde Alarcos» (Cancionero de romances, p. 186) fue fechado por Menéndez Pidal como anterior al año $1470^{43} \mathrm{y}$, como tantos

41. R. Menéndez Pidal, Romancero hispánico, vol. 1, p. 269 y 289-292 ; G. Di Stefano, Romancero, p. 391; S. Armistead y J. H. Silvermann, «Gaiferos y Waltharius: Paralelismos adicionales», en Homenaje al Profesor Antonio Vilanova, Barcelona, Universidad, 1989, T. I, p. 31-43; V. Millet, Épica germánica y tradiciones épicas hispánicas: Waltharius y Gaiferos. La leyenda de Walther de Aquitania y su relación con el romance de Gaiferos, Madrid, Gredos, 1998.

42. S. Singer, op. cit., vol. 7, asiento 4.7.1. Wer einen liebt, zügligt ihn y asiento 7.3. Wenn man raten kann, dem kann man helfen.

43. R. Menéndez Pidal, Romancero hispánico, vol. 2, p. 19-20. 
romances de origen carolingio, es un drama de amores. La infanta pide a su padre casarse con el Conde Alarcos, pero éste ya está casado. El Conde es presentado como un amante fiel:

$$
\begin{aligned}
& \text { [...] no pueden por mí dezir } \\
& \text { aquesto que yo dezía } \\
& \text { qu'en tiempo que yo seruí } \\
& \text { vna que tanto quería } \\
& \text { si muy bien la quise entonces } \\
& \text { agora más la quería } \\
& \text { mas por mí pueden dezir } \\
& \text { quien bien ama tarde oluida (p. 186). }
\end{aligned}
$$

El verso «quien bien ama tarde oluida» no es sino un refrán de una antigua tradición. Su atestación más primitiva se remonta al poeta inglés Robert Pates (1162-1172): «Si set amor uerus, capit hic obliuia serus». Posteriormente, encontramos otras versiones latinas derivadas de este refrán: «Non laudem meruit dilectio, quae cito transit» y "Verus amor, vera si mens, oblivio sera» (Werner N 195 y V 25). Su versión francesa más antigua es de Huon de Rotelande (1174-1191) en su obra Ipomedon: "Cil ki bien eyme, tart oblie» y luego en la Folie de Tristan (I, v. 702): «Hom ke ben aime tart oblie». A partir de aquí sus recurrencias son múltiples ${ }^{44}$. Al igual que la materia de este romance, el refrán es herencia francesa. En España se difundió especialmente entre la poesía de cancionero, por ejemplo en un poema de Juan Álvarez Gato dirigido a don Pedro de Mendoza, en el que revela los amores de Guevara:

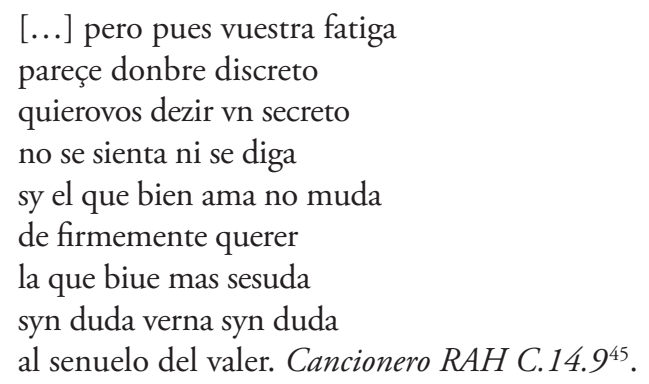

44. Por ejemplo su cita en el manuscrito del colegio Corpus Christi de Cambridge que publica Le Roux de Lincy en Le livre des proverbes français, préface de Pierre Boutang, París, Paulin Éditeur, 1842 (reimp. París, Hachette Livre, 1996), p. 950. Véase su registro en S. Singer, op. cit., vol. 7, asiento 4.2.2. Wahre Liebe vergeht und vergisst spät oder nie.

45. B. Dutton (ed.), El cancionero del siglo XV, T. 1, Salamanca, Universidad de Salamanca, 1990-1991, p. 554a 
Santillana lo utilizó en un soneto $\left(\mathrm{N}^{\circ} \mathrm{xvi}\right)$ sobre la consolación de amor:

Amor, debdo e voluntad buena

doler me fazen de vuestra dolor, e non poco me pena vuestra pena, e me tormenta la vuestra langor.

Çierto bien siento que non fue terrena aquella flamma nin la su furor que vos inflama e vos encadena, infima carcel, mas çeleste amor.

Pues, ¿que dire? Remedio es olvidar; mas animo gentil atarde olvida, e yo conozco ser bueno apartar. Pero deseo consume la vida; assi diria, sirviendo, esperar ser qualque alivio de la tal ferida ${ }^{46}$.

y hasta entró en su colección de refranes, que tanta conexión tiene con la lírica: "Bien ama quien nunca oluida», Refranes (No 126), que en la edición de 1541 se glosa: «Especial señal de amor es el continuado agradecimiento» ${ }^{47}$. Se trata, pues, de un refrán para indicar el amor fiel. Por tanto, la utilización por el Conde Alarcos de este refrán tiene la fuerza de una verdadera profesión de amor. El refrán ha prestado su campo semántico al romance que luego se desarrollará como un drama de amores.

En fin, se puede constatar que los romances juglarescos de tema carolingio son propensos no sólo a incluir refranes, sino a colocar toda suerte de versos proverbiales. Pero así como todo verso de romance puede proverbializarse, todo tipo de romance puede aceptar versos proverbiales.

Dejamos así atrás los romances carolingios del Cancionero de romances y nos internamos en los históricos. El «Romance de las quejas de doña Jimena», «Día era de los reyes» (Cancionero de romances, p. 224-225), se conserva en tres versiones (Antología $\mathrm{N}^{\circ} 30$ ), conteniendo todas dos refranes. En opinión de Menéndez Pidal, estamos en presencia de romances anteriores a la crónica de $1344^{48}$. Doña Jimena pide justicia al rey porque el Cid ha matado a su padre: «Rey que no haze justicia / no deuia de reynar» (p. 225). Estos versos presentan diluido uno de los refranes jurídicos más importantes de la Edad

46. Marqués de Santillana, Comedieta de Ponça. Sonetos. Ed. M. Kerkhof, Madrid, Cátedra, 1986, p. 143.

47. H. O. Bizzarri, «La glosa de 1541 a los Refranes que dizen las viejas tras el fuego», Olivar, 2 (2001), $\mathrm{N}^{\circ} 125$.

48. R. Menéndez Pidal, Romancero hispánico, vol. 1, p. 219-220. 
Media con el cual se definía la naturaleza del rey: «Rex a recte regendo». Su atestación más antigua se halla en una epístola de Horacio: «At pueri ludentes, rex eris, aiunt / si recte facies»; parece haber llegado a San Agustín, De ciuitate Dei (v, 12): «[...] cum et reges utique a regendo dicti melius iudicantur, ut regnum a regibus, reges autem, ut dictum est, a regendo", y de aquí la tomó San Isidoro, Etimologías (ix, 3): «Reges a regendo vocati; sicut enim sacerdos a sanctificando; ita et rex a regendo. Non autem regit, qui non corriget. Recte igitur faciendo reges nomen tenetur, peccando amittur. Unde et apud ueteres tale erat prouerbium: Rex eris si recte facies, si non facias, non eris ${ }^{49}$. El refrán postulaba la idea de que lo que distingue al rey en cuanto tal es su facultad de hacer cumplir la justicia; cuando así no lo hacía, se transformaba en un tirano. Desde el punto de vista teórico nos muestra de qué manera un romance se apropia de una formulación tradicional y la incorpora como verso de romance.

El segundo caso presenta la cita expresa de un refrán:

$$
\begin{aligned}
& {[. . .] \text { siempre lo oi dezir }} \\
& \text { y agora veo que es verdad } \\
& \text { que el seso de las mugeres } \\
& \text { que no era natural } \\
& \text { hasta aqui pidio justicia } \\
& \text { ya quiere con el casar (p. 225). }
\end{aligned}
$$

La idea del poco entendimiento de la mujer es muy frecuente en el refranero: "Certum est enim longos esse crines omnibus, sed breves sensus mulieribus», Cosmas, Chronica Boemorum (ca. 1110), «Longam cesariem, sed cortam femina mentem», Proverbia Wratislaviensia (ca. 1412), etc. ${ }^{50}$. Pedro del Corral tal vez se haga eco de este refrán en el siguiente pasaje de su Crónica sarracina:

Ya sabedes, señor que las mujeres son de libiano seso e non se pueden guardar que non yerren, ansi commo lo fazen los omnes, que han mayor conplision, e non se deben mober tan ligera mente; e pues vos, señor, sabeis que esto que yo digo es verdad, non me debriades probar por tal manera commo esta, ca por ventura yo cuidaria que me lo deziades de verdad e yo quedaria engańada e otorgarvos todo lo que me demandasedes; e, seńor, podria ser pensar vos que yo lo fazia con maldad que en mi oviese, e que ansi como a vos

49. J. Balog, «Rex a recte regendo», Speculum, 3 (1928), p. 580-582.

50. Véanse más versiones en S. Singer, op.cit, asiento 1.2.2.3 y 1.2.2.4 Der Sinn und das Herz sind launish und flatterhaft. 
lo otorgase, que ansi lo otorgaria a otro, si se atreviese a me lo dezir, e por esta guisa yo perderia vuestro amor, sin culpa mia, ca por el ligero seso que las mugeres avemos e por ser requerida por la via que vos me requerides, fazia yo el yerro, si vos non lo dixesedes por me probar, ca nunca puede fazer maldad la muger que non es seguida ${ }^{51}$.

Sin embargo, la primera aparición castellana de este refrán es la que nos documenta este romance. Para nuevas recurrencias hay que esperar hasta el siglo XVII. Cervantes lo presenta con alguna variante: «el consejo de la mujer es poco, y el que no le toma es loco» (Quijote, II-VII, p. 606) y tras él Correas: «El consejo de la mujer es poco, y el que no le toma es loco», Vocabulario (E 376). O’Kane encontró otras versiones entre los sefardíes: «El consejo de la mujer es poco, mas quien no lo toma es loco» $\mathrm{y}$ «El meollo de la mujer es poco, el que (mas quien) no lo toma es loco» ${ }^{52}$. Como se ve, se trata de un refrán con una tradición activa aún en tiempos modernos, de la cual el «Romance de las quejas de doña Jimena» nos presenta su versión más antigua $^{53}$. El rey Alfonso expresa este refrán antifeminista, pues encuentra contradictorio el reclamo de Jimena, no obstante, se hace eco de él.

$\mathrm{El}$ «Romance de la muerte de la reyna Blanca», "Doña María de Padilla» (Cancionero de romances, p. 234-235) se inspira en el asesinato de la esposa de Pedro I ocurrida en 1361. Narra los mismos episodios que Ayala en su crónica, pero, a diferencia de éste, es hostil al rey y a María de Padilla. El romance representa, pues, la opinión popular contemporánea a los hechos ${ }^{54}$. Doña María ordena a Yñigo Ortiz ir a matar a la reina doña Blanca, pero éste se niega argumentando: "quien mata a su señora / haze aleue a su señor» (p. 234). El refrán tiene también carácter legal, expresando en una práctica fórmula la idea corporativista del reino: atacar una de las posesiones del rey es atacar al rey mismo. En la Partida II (Tít. XIV, Ley 1) se explica que quien comete adulterio con la mujer del rey comete traición al mismo rey:

51. Cito por R. Menéndez Pidal, Floresta de leyendas heroicas españolas. Rodrigo, el último godo, vol. 1. Edad Media, Madrid, Espasa-Calpe, 1942, p. 79-80. La crónica de Pedro del Corral puede leerse ahora completa en la edición de J. D. Fogelquist, Pedro del Corral, Crónica del rey don Rodrigo postrimero rey de los godos (Crónica Sarracina), Madrid, Castalia, 2001, 2 vols.

52. O’Kane, Refranes y frases proverbiales..., p. 89 y 159.

53. Véase el comentario de H. O. Bizzarri, «El consejo de la mujer es poco, y el que no le toma es loco", en Carlos Alvar (coord.), Gran Enciclopedia Cervantina, T. 4, p. 3910.

54. J. R. Lomba y Pedraja, «El rey don Pedro en el teatro», en Homenaje a Menéndez Pelayo en el año vigésimo de su profesorado, vol. 2, Madrid, 1899, p. 257-339; P. Díaz-Mas, Romancero, p. 160. 
«Por esto harian traicion conocida los que lo hiciersen, e debe haber tal pena, como si los hubiesen hecho contra el rey mismo" ". Ahora se comprende el alcance del verso del romance: matar a doña Blanca es hacer traición al rey. Pero esto se expresa en una fórmula común al romancero y al refranero.

Tomemos ahora un par de ejemplos de romances novelescos. El romance «Essa guirnalda de rosas» (Di Stefano $\mathrm{N}^{\circ} 25$ ) consiste en un rápido diálogo entre una madre y su hija quien ha advertido que alguien corteja a la niña. Como bien señala Di Stefano, la joven narra el encuentro amoroso «entre símbolos delicados y crudezas realistas ${ }^{56}$. La madre se preocupa por la deshonra de la hija, pero ella reinvindica su amor con un proverbio: «más vale un buen amigo que no ser malmaridada» (p. 178). La misma frase se halla en boca de Melibea cuando sus padres planean su casamiento: «Dexenme mis padres gozar del, si ellos quieren gozar de mi. No piensen en estas vanidades ni en estos casamientos: que más vale ser buena amiga que mala casada ${ }^{57}$. Los paralelos entre ambas escenas son muchos, pero cabe advertir que cada texto cita el refrán a su modo. El romance pone el acento en el enamorado y se sirve de un vocablo, «malmaridada» que pertenece a la fraseología del romancero. Rojas, por su parte, pone el acento en la voluntad de Melibea y utiliza un término más general a la lengua, «mala casada». Correas documenta este refrán, tal vez de la lectura misma de La Celestina, pero añade una variante que testifica su existencia oral aún en el siglo XVII: "Mas vale ser buena amiga que mala casada; [o mas vale ser buena] enamorada...», Vocabulario (M 637). Di Stefano señaló una versión francesa de este refrán contemporánea al romance: «Car il vault myeux avoir amy / qu'estre mal mariee» ${ }^{58}$.

El romance de la Julianesa, «Arriba, canes, arriba» (Di Stefano $\mathrm{N}^{\circ} 44$ ), es un poema tradicional y seguramente fragmentario. Menéndez Pidal señaló influencia en él del poema francés Aye d'Avignon, mientras que Di Stefano y Díaz-Mas lo han vinculado con «Moraima y Galván», aunque el final de este romance debería de ser diferente ${ }^{59}$. Efectivamente, ambos romances exponen la misma situación, pero vista desde puntos diferentes. «Moraima y Galván» narra desde la corte del rey moro donde está cautiva Moraima; el romance de la Julianesa desde el punto de vista del marido que busca desesperadamente

55. Alfonso X, Las Siete Partidas. Ed. J. Sánchez-Arcilla, Madrid, Editorial Reus, 2004, p. 249.

56. G. Di Stefano, Romancero, p. 177.

57. Fernando de Rojas, La Celestina. Ed. H. López Morales, introducción de Juan Alcina, Barcelona, Planeta, 1980, p. 208.

58. Op. cit., p. 178.

59. R. Menéndez Pidal, Romancero hispánico, vol. 1, p. 262-267; G. Di Stefano, Romancero, p. 204; P. Díaz-Mas, Romancero, p. 247, P. Benichou, op. cit., p. 63-68. 
a su esposa. "Moraima» es más explícitamente sangriento: "Alzó la su mano el moro, un bofeton le fue a dare: / los dientes teniendo blancos en sangre buelto los hae» (Di Stefano $N^{\circ} 42$, p. 203). El romance parece sugerir el fin trágico de Moraima, pues ella reafirma su amor marital: "Yo muera como cristiana y tambien por confesare / mis amores verdaderos de mi esposo naturale» (p. 203), aunque hay otras versiones (Primavera, $\mathrm{N}^{\circ} 122$ y 123) que finalizan la aventura de una manera feliz que, según Di Stefano, "saben a continuación postiza» (p. 203). El romance de Julianesa evita esta escena sangrienta, que a mi parecer está aludida en los primeros versos, no porque se mate a la cautiva, sino porque su esposo tiene miedo de que se lo haga: "iArriba, canes, arriba, que rabia mala os mate! / en jueves matais el puerco y en viernes comeis la sangre». Según Díaz-Mas, el primer verso aludiría a los moros, frecuentemente motejados como perros y el segundo "[...] podría tener como trasfondo la transgresión de prescripciones religiosas alimentarias: la interdicción de comer carne de cerdo para los musulmanes y la abstinencia cristiana de los viernes» ${ }^{60}$. Pero también me pregunto si este verso no podría tener contacto con el refrán que inserta Montoro en un poema contra Rodrigo Cota en el que le recuerda sus orígenes conversos:

$$
\begin{aligned}
& \text { Gentilhombre de buen zelo, } \\
& \text { de linda saviduría, } \\
& \text { ¿quién hiziera a vuestro agüelo } \\
& \text { que dixera sin reçelo } \\
& \text { "iVoto a la Virgen Maria!»? } \\
& \text { ¡Oh savio de los loados, } \\
& \text { ante quien demas alterco, } \\
& \text { en negocios mejorados, } \\
& \text { con parientes convidados } \\
& \text { matar en savado puerco! (p. 169). }
\end{aligned}
$$

Que la inserción de refranes en la poesía tradicional es un fenómeno anterior al siglo XVI es un hecho que se desprende de esta somera revisión del Cancionero de romances. Martín Nucio recogió romances que son bastante anteriores al siglo XVI, algunos, como el referido a María de Padilla, se remontan al siglo XIV. Vuelvo sobre una pregunta previa: ¿Es este maridaje genético? Dicho en otras palabras, ¿los refranes fueron parte constitutiva de los poemas que los incorporan desde su primer acto compositivo o son más bien un efecto de la progresiva elaboración del «estilo tradicional»? Tal vez la observación de romances conservados en más de una versión pueda develarnos este interrogante.

60. P. Díaz-Mas, Romancero, p. 247. 
Tomamos primeramente el romance "Amores trata Rodrigo", que se nos ha conservado en cuatro versiones (Antología $\mathrm{N}^{\circ} 3$ ). Es claro que procede de la crónica de Pedro el Corral (caps. 172 y ss.) y que su origen debió de ser anterior a mediados del siglo $\mathrm{XVI}^{61}$. Fue tomado por Menéndez Pidal como ejemplo de un romance compuesto por un juglar o un poeta culto que adquirió luego el estilo popular. El romance trata del tema de la seducción de la Cava. La versión extensa resume muchos capítulos de la crónica de Del Corral y, por tanto, posee un estilo eminentemente narrativo. Nos importan más bien las tres versiones breves que representan tres performances distintas. La que primero coloca Menéndez Pidal $\left(\mathrm{N}^{\circ} 3\right)$, procedente de un pliego gótico de Praga, es la que más sigue la versión extensa. La $\mathrm{N}^{\circ} 3$ a, procedente de un pliego suelto de la Universidad de Cracovia publicado en Granada por Hugo de Mena en 1570, acentúa el estilo popular. Cuando el rey propone amores a la Cava, ésta responde equívocamente: «Pienso que burla tu Alteza / o quiere probar el vado» (p. 84). «Probar el vado» es en realidad una frase proverbial utilizada para indicar que alguien quiere transgredir un límite: «Enpero, sé cierto que el rey e el papa e el çapatero, todos pasan por aquel vado» Corbacho (p. 247) ${ }^{62}$. La última versión $\left(\mathrm{N}^{\circ} 3 \mathrm{~b}\right)$ es la más popular, pues no sólo conserva la frase proverbial, sino que además agrega unos versos a la petición de Rodrigo que acentúan su presión: "[...] mira, que lo que el rey pide / ha de ser por fuerza, o por grado» (p. 86). Tal vez estos versos hagan alusión al tan difundido refrán "Allá van leyes ó quieren reyes» con el que se aludía habitualmente a la arbitrariedad de la justicia real ${ }^{63}$. Tal vez se trate de uno de los tantos versos proverbiales a los que tiende la fraseología de los romances, pero siempre aludiendo a la arbitrariedad del poder real. No creo que la adición de este verso sea agena a aquel que trae la frase proverbial. Para decirlo en términos de Diego Catalán, el cambio en el romancero es ecosistemático ${ }^{64}$, y aquí es claro que la adición de la frase

61. R. Menéndez Pidal, Romancero hispánico, vol. 1, p. 165; R. Menéndez Pidal, Floresta de leyendas heroicas españolas, vol. 2, p. 16-21 (los romances llevan los números 3 y 6); P. DíazMas, Romancero, p. 134.

62. Véanse las formas que trae Francisco de Espinosa: «Comigo quieren todos pasar el vado», «andáis tentando el vado», Refranero. Ed. E. O’Kane, Madrid, BRAE, 1968, p. 237.

63. Véase sobre este refrán A. G. Solalinde, "Allá van leyes o mandan reys», RFE, 3 (1916), p. 288-300 y H. O. Bizzarri, «Allá van leyes do quieren reyes» en Gran Enciclopedia Cervantina, vol. 1, p. 380-381.

64. D. Catalán, «El romance tradicional un sistema abierto», en D. Catalán, S. Armistead, con la colaboración de A. Sánchez Romeralo (eds.), El romancero en la tradición moderna. I coloquio internacional, Madrid, Cátedra-Seminario Menéndez Pidal y Rectorado de la Universidad de Madrid, 1973, p. 181-205. 
proverbial señalando la quiebra de un límite dio pie a la inserción de otro verso que habla de la imposición de otro límite.

El romance «Estando el rey don Fernando» (Antología No 95 ) nos presenta otro caso de reelaboración de un romance tradicional. Nos han quedado de él dos versiones, la más breve recogida por Pérez de Hita y una más extensa en un pliego suelto del siglo XVI. Menéndez Pidal calificó a este romance como un último eco de los llamados fronterizos ${ }^{65}$. El poema trata sobre la heroica muerte de don Alonso de Aguilar en la Sierra Bermeja en el año 1501. El poema contiene tres partes: la arenga del rey para animar a sus hombres a ir contra los moros, la lucha agónica de don Alonso y el planto por su muerte. La versión breve es el relato desnudo de la muerte del héroe sin ninguna otra implicancia. La versión extensa, por el contario, transforma al romance en una alabanza a la vida de la fama, nacida a partir de un hecho heroico. Es por eso que en la respuesta de don Alonso a la arenga del rey se agregan un par de versos proverbiales que retoman la manida idea de la vida de la fama del hombre, que ya hemos encontrado en otros romances: «Mejor es aqui morir ejercitando las armas / que no vivir con deshonra con vida tan aviltada» (p. 190). En esta versión don Alonso no va contra los moros por sólo un ímpetu de heroismo irreflexivo, sino que hay una firme voluntad de morir con honra antes que llevar una vida anodina. El verso final del romance volverá sobre esta idea. El rey Fernando halla consuelo de la muerte de su heroico vasallo, pues ha alcanzado la vida de la fama: «el rey hubo gran placer en que muerto lo cobraba / puesto que allí muriera, su fama siempre volaba» (p. 192). Tal vez la idea que transmite el refrán "Murio el omne, mas non murio el su nonbre» hacía que se lo aplicara a relatos que tuvieran cierta historicidad. Recuérdese que ya anteriormente lo había utilizado Juan Manuel en el ejemplo XVI de su Conde Lucanor, en el que se relata la victoria del conde Fernán González sobre el rey don Sancho de Navarra y su lucha inmediata con el conde de Tolosa que venía en socorro del rey ${ }^{66}$. Se trata de un ejemplo inspirado en la Estoria de España (cap. 696) y en el Poema de Fernán González (cc. 334-385), dos textos que le aseguraban la historicidad del relato. Don Juan Manuel, como tantas veces a lo largo de su obra, no repite el relato tal como lo presentan sus fuentes, sino que lo reelabora de

65. R. Menéndez Pidal, Romancero hispánico, vol. 2, p. 57-58.

66. Ejemplo comentado por M. R. Lida de Malkiel, «Tres notas sobre don Juan Manuel», en Estudios de literatura española y comparada, Buenos Aires, Eudeba, 1969, p. 106, D. Devoto, Introducción al estudio de don Juan Manuel y en particular de El Conde Lucanor. Una bibliografía, París, Ediciones Hispano-Americanas, 1972, p. 398-399, R. Ayerbe-Chaux, El Conde Lucanor. Materia tradicional y originalidad creadora, Madrid, José Porrúa Turanzas, 1975, p. 88-90. 
una manera personal. Lo que era un consejo de Nuño Laínez motivado por la protesta de las huestes, en la crónica lo transforma en un consejo personal del caballero y adiciona en la respuesta del Conde el motivo más destacable de su relato, un refrán:

\section{[...] et dexar de defender la tierra, que bien lo podrian fazer, mas que les contesçeria commo dezia el vierbo antigo: Murio el onbre et murio el su nonbre; mas si quisieramos olbidar los viçios et fazer mucho por nos defender et leuar nuestra onra delante, diran por nos, depues que moriremos: Murio el omne, mas non murio el su nonbre ${ }^{67}$.}

Sin embargo, los textos predecesores no incluyen el refrán en el episodio. Es posible que su inserción estuviera sugerida por el texto mismo de la crónica: «Et el omne que quiere estar uicioso et dormir et folgar, non quiere leuar al deste mundo; et del omne tal como este muerense sos fechos el dia que sale deste mundo» ${ }^{68}$. En suma, tanto el romance como el relato de don Juan Manuel se hacen eco de un refrán que solía aplicarse ya a relatos históricos, ya a pseudohistóricos, pero siempre servía para realizar una alabanza a la perdurabilidad de los buenos hechos, especialmente los heroicos. Una última observación: tanto este romance como "Amores trata Rodrigo" nos ofrecen claros ejemplos de performance de romances. Los refranes pueden hallarse en algunas de sus versiones, adicionados en el hecho mismo de la reactualización del poema.

\section{Nuevas perspectivas sobre un viejo problema}

He tomado el Cancionero de romances de Martín Nucio como atalaya para observar la relación entre refranes y romances y ello me ha servido para advertir que la presencia de refranes en romances se halla ya en versiones romanceriles del siglo XIV (pensemos en el romance de Gaiferos o «Las quejas de dońa Jimena»), dos siglos antes que el proceso inverso. Tal vez el romancero debió esperar a transformarse en una verdadera moda para que se produjera la lexicalización de versos de romances.

67. Cito por J. M. Blecua (ed.), Don Juan Manuel. Obras completas, vol. 2, Madrid, Gredos, 1983, p. 133.

68. R. Menéndez Pidal (ed.), Primera crónica general de España, con un estudio actualizador de Diego Catalán, vol. 2, Madrid, Gredos, 1977, p. 398. 
Romances y refranes utilizaban parecidos esquemas expresivos, del mismo modo que proverbios y sentencias. Y así como esto posibilitó la convivencia de estas formas en las mismas colecciones, ello creó las bases para la convivencia de refranes y romances. La presencia de refranes en la lírica de los siglos XV a XVII no es algo excepcional. Ellos se pueden encontrar tanto entre los versos de poetas eruditos como en composiciones populares, tales como el villancico. Pero a diferencia de la relación que los refranes mantienen con la poesía épiconarrativa, en la poesía lírica el refrán suele jugar el papel de estribillo o de versos que de alguna manera poseen una función especial. En los romances, por el contrario, se metamorfosean en versos de estilo tradicional, gracias a esos rasgos fraseológicos comunes. A partir de aquí se van a dar una serie de procesos. Por ejemplo, el préstamo del campo semántico, la creación de pseudorefranes, la inserción de refranes diluidos, etc. Pero también se ha observado que este cruce no supone que necesariamente se deba producir desde los primeros momentos de creación de una versión romanceril. Muy por el contrario, siempre es un efecto de la performance de un romance $\mathrm{y}$, como tal, pertenece a una actualización puntual.

Lo más importante es advertir que este cruce en dos direcciones no es un efecto de la tradición moderna: se encontraba ya en la tradición antigua y, en el siglo XVI, cuando los versos de romances comenzaban a lexicalizarse, los refranes hacía ya siglos que habían entrado en contacto con ellos. 